\title{
Policy Options for India's Edible Oil Complex
}

\section{A AMARENDER REDDY}

Stagnating oilseed yields for the last two decades and an inefficient and underutilised processing sector have resulted in an uncompetitive complex in India. The country's commitments at the World Trade Organisation have led to increased edible oil imports and a simultaneous decline in area under oilseeds. India needs a long-term edible oil policy to improve competitiveness by bridging the existing technology and yield gaps.

A Amarender Reddy (aareddy@asci.org.in) is with the Administrative Staff College of India, Hyderabad.
$\mathrm{I}$ ndia's edible oil imports are likely to register a surge to around 7.5 million tonnes (mt) in the oil-marketing year 2009. On an average in the last five years, India produced about 6-7 $\mathrm{mt}$ and imported between 4-5 $\mathrm{mt}$ of edible oils annually to meet its domestic consumption. India's oilseed and edible oil sector is exposed to international markets and influence of policy options like the minimum support price (MSP) and other market interventions are limited. Historically, India has been a net importer of edible oils. After a period of stagnation in oilseed production and large edible oil imports, the government of India started the Technology Mission on Oilseeds (тмоs) in 1987, which increased oilseed production and made India selfsufficient by the early 1990s. This is now widely known as the "yellow revolution".

A commendable aspect of this yellow revolution was an integrated effort led by the Ministry of Agriculture, National Oilseeds and Vegetable Oils Development (NOvOD) Board and National Agricultural Cooperative Marketing Federation (NAFED), for providing extension and market support; and research and development support provided by the Indian Council of Agricultural Research (ICAR) and State Agricultural Universities (sAus). The improved technology helped in enhancing productivity of oilseeds; while a higher minimum support price and high import tariff rates acted as an incentive for expanding area and input use under oilseeds. However, this was not sustained beyond the early 1990s, as low international prices and reduction in import tariffs due to commitments made at the World Trade Organisation (wто) on edible oils (especially soya oil) resulted in a surge in import of edible oils to the extent of $5 \mathrm{mt}$ annually by late 1990s as the bound tariff level on soya oil is only $45 \%$. The resulting low oilseed prices hindered wider adoption of improved technology in oilseed growing areas. Most of the oilseed farmers either shifted to other crops or kept their lands fallow if the lands were not suitable for any other crop.

\section{Shifting Policy since the 1990s}

Since the late 1990s, India resorted to an ad hoc and flexible import regime to manage domestic shortfall in production. Prior to 1994, edible oil was on the negative list of imports, and only State Trading Corporations (STCS) were allowed to import it. Beginning in 1994, tariff rates of edible oils were liberalised in a phased manner. In 1994, palmolein oil was placed under the Open General License (OGL). Subsequently, imports of other edible oils were also placed under OGL. Between 2000 and 2008, import duties were revised more than 15 times. The basic objective of adjustment in import tariff rate is to meet the shortage in domestic production. The period from 1994 can broadly be divided into three distinct phases: the first between 1994 and 1998, when customs duty on edible oils progressively came down to reach a low of $15 \%$ in 1998 , the second after 1999, when such duties witnessed a general upward trend to reach a high of $99 \%$ for refined palmolien in 2005 , and the third phase from late 2005, when once again duties on edible oils decreased and reached the lowest (7.7\%) in 2008.

\section{Spillover Effects of Pricing}

The MSP is also an important variable which influences the profitability of oilseed crops in years of low international prices. The 
MSP has been steadily increasing since the 1980s; but the effectiveness of procurement at MSP by state agencies is questionable for oilseeds, which is not economical due to scattered distribution over wide areas. The lack of a long-term policy, and a higher dependence on international markets resulted in an increase in fluctuations in domestic edible oil prices. Uncertainty in the policy environment also adversely affects the farmer's decision process in allocation of area to oilseeds. The decrease in production of oilseeds also reduces raw material availability for processing units, which were already suffering from under capacity utilisation. It also adversely affected investments in oilseed processing sector, which is characterised by outdated processing units. The efforts in research and development by ICAR and sAus have also taken a back seat as the area under oilseeds decreased. Some studies (Mruthyunjaya 2005 and Chand 2003) have pointed out that despite a competitive oilseed sector, an inefficient edible oil processing sector has made India less competitive in its edible oil complex (oilseed and processing sector). A study by Reddy (2009) estimated that reducing tariffs in the oilseed sector has a negligible effect on trade creation, consumer surplus and also on government tariff revenue. However, a decrease in tariffs on edible oils to $30 \%$ and to o $\%$ levels will increase edible oil imports by 30\% and 50\%, respectively over the base year 2008 imports. Further, the option of import of oilseeds for increasing the capacity utilisation of the domestic oilseed processing sector is not cost-effective as there are considerable handling and transport costs involved when compared to the import of edible oils. Hence, the only option is to increase domestic production of edible oils.

\section{Wide Technology Gaps}

The technology levels of the edible oil processing sector are heterogeneous, with traditional ghanies with low capacity on the one hand and solvent extractors with modern plants on the other. Due to smallscale reservation of the oilseed processing sector for a long period, the average size of processing units is very small besides having outdated technology. The average capacity of oilseed expelling plants varies from 0.06 tonnes per day for small ghanies to 9 tonnes per day for large-scale expellers. A wide gap between the new and old technology levels makes technology upgradation in ghanies difficult, which requires replacing all equipment and fixed capital and shifting over to entirely new technology, and skill levels which are mostly beyond the capabilities of existing processing units. Hence the solvent extraction and large-scale expeller units are coming in organised sector from an entirely new stream of entrepreneurs. Increasing efficiency and capacity utilisation of the existing processing sector through modernisation is important to reduce the cost of processing oilseeds. There is a need to encourage and simplify the norms to facilitate upgradation of technology and innovation in the processing sector. Support for development and diffusion of intermediate processing technology with medium-scale units (which has already been developed by the ICAR under the ongoing Integrated Scheme of Oilseeds, Pulses, Oil Palm and Maize (Isopom)) which can be easily acquired or upgraded by the existing owners of small-scale expeller units is essential for making the processing sector economically viable. Providing easy credit availability for small ghanies and investment subsidies for upgradation in 
ghanies and oilseed expellers is essential to make edible oil sector competitive.

\section{MSP vs Cost of Production}

In the context of crop profitability, the frequently used policy variable to influence demand and supply of a particular crop in India is the announcement of minimum support prices (which is also the government procurement price if market price goes below the announced price) before the cropping season. This has been effectively used in the case of both paddy and wheat, and has proved very successful in making India self-sufficient in foodgrains. Growth in MsP is lower for oilseeds compared to competing crops like maize and jowar and also paddy since 1991. We have also compared the cost of production and MSP per quintal of major competing crops for groundnut for the triennium ending (TE) 2003. It shows that for paddy and wheat, the MSP is higher than their cost of production by about $19 \%$ and $27 \%$ respectively, while for groundnut it is more by $7 \%$. For jowar and barley, even the cost of production has not been covered by the MSP. Hence, in the short run there is good scope for expanding area under groundnut by replacing jowar and bajra, which require similar agro-climatic conditions and in most of the regions they compete both under rainfed and irrigated-dry lands.

Cross elasticity among different domestically produced oilseeds like groundnut oil and imported oils like palm oil and soya oil makes it practically impossible to have high MSP in the long run in the post wTo scenario (as palm oil and soya oil were available in international market at lower prices) without a high subsidy and a wider public distribution system (PDS) for edible oils. At the same time, procurement at MSP and a wider adoption of PDs in case of oilseeds which are produced and consumed thinly, and spread over large and scattered areas is not economical for any government agency.

Srinivasan (2004) studied the impact of protection to edible oil sector through a hike in tariff rate and concluded that it reduces consumer surplus, increases producer, processor and government surplus. Overall, it results in net loss to the economy. Another study by Gulati et al (1996) estimated that under the free trade scenario, if we align our domestic prices with international prices, our domestic prices will fall by $38 \%$ for edible oils, and the supply of oilseeds would reduce by about 10\%. Overall prices will come down, and domestic demand will increase with a consequent increase in import of edible oils.

One centrally sponsored Isopom during the Tenth Five-Year Plan that is being implemented with effect from 2004 is a step in the right direction. The components of the mission are, (a) improvement of crop production and protection technologies for realising higher yields and profit to farmers, (b) improvement of processing and post-harvest technology to minimise the losses and increase the oil yield from both traditional and non-traditional sources of oil, (c) strengthening the input support system to ensure availability of the right kind of seed, fertilisers, pesticides, irrigation, credit, etc, and to create awareness among farmers about the potential of the farm-worthy technology through massive transfer of technology programmes, and (d) improvement of post-harvest operations for effective procurement, handling and disposal, including price support system to farmers and financial and other supports to processing industry.
The components of price support and input supply made significant improvements in increase in area and production during the period of yellow revolution as well as in green revolution. However, the above steps only give results in the long run with sufficient protection from the low international prices in the medium term. The policy of maintaining a price band for all edible oils through adjustment of import tariffs is a precondition to rejuvenate the yellow revolution and to provide stable prices for farmers and processors.

\section{REFERENCES}

Chand, Ramesh (2003): "India's Oilseed Sector and WTO", paper presented at the National Seminar on Stress Management in Oilseeds for Attaining Self-reliance in Vegetable Oils, Indian Society of Oilseeds Research, Directorate of Oilseeds Research, Andhra Pradesh, 28-30 January.

Gulati, Ashok, A Sharma and D S Kohli (1996): "Selfsufficiency and Allocative Efficiency - Case of Edible Oils", Economic \& Political Weekly, Vol 31, No 13, 30 March.

Mruthyunjaya (2005): "Improving Technical Efficiencies to Counter Import Threat of Edible Oils in India" (New Delhi: National Centre for Agricultural Economics and Policy Research).

Reddy, A A (2009): "Impact of WTO on Edible Oil Complex" (Pakistan: South Asia Network of Economic Research Institutes).

Srinivasan (2004): "Managing Price Volatility in an Open Economy Environment: The Case of Edible Oils and Oilseeds in India", International Food Policy Research Institute, MTID Discussion Paper No 69.

\section{䇾 CENTRAL FOOD TECHNOLOGICAL RESEARCH INSTITUTE (Council of Scientific \& Industrial Research) \\ (An ISO 9001:2000, ISO 14001:2004 and 17025:2005 (NABL) Organization) MYSORE-570 020, INDIA (CFTRI website : http://www.cftri.com) \\ RECRUITMENT FOR TECHNICAL POSITIONS ADVERTISEMENT NO. REC 3/2009 \\ APPLY ONLINE ON OR BEFORE 11.11.2009}

Central Food Technological Research Institute is a premier Research Institution under the Council of Scientific \& Industrial Research (CSIR), New Delhi and is engaged in research and development in the field of Food Science and Food Technology. Over the years, the Institute has been continuously enhancing its capabilities to achieve high quality research through training, strategic innovations and recruitment of qualified personnel for its R\&D activities.

CFTRI is looking for bright, dynamic and highly motivated candidates for the following technical positions:-

\begin{tabular}{|l|l|c|c|c|c|}
\hline $\begin{array}{l}\text { SI. } \\
\text { No. }\end{array}$ & $\begin{array}{l}\text { Details of the } \\
\text { Posts }\end{array}$ & $\begin{array}{c}\text { Pay Details } \\
\text { (Pay+ } \\
\text { Grade Pay) }\end{array}$ & Total pay & No. of Post(s) & $\begin{array}{c}\text { Upper } \\
\text { Age } \\
\text { Limit }\end{array}$ \\
\hline 1 & $\begin{array}{l}\text { Technical Staff } \\
\text { in Group-III (1) }\end{array}$ & $\begin{array}{c}\text { Rs.9300+ } \\
\text { Rs.4200 }\end{array}$ & $\begin{array}{c}\text { Rs.20861/- } \\
\text { (if accommodation } \\
\text { provided-Rs.18161/-) }\end{array}$ & $\begin{array}{c}10 \\
\text { [SC-2; ST-1; } \\
\text { OBC-3; UR-4] }\end{array}$ & $\begin{array}{c}28 \\
\text { Years* }\end{array}$ \\
\hline 2 & $\begin{array}{l}\text { Technical Officer } \\
\text { in Group-III (3) }\end{array}$ & $\begin{array}{c}\text { Rs.12540+ } \\
\text { Rs.4600 }\end{array}$ & $\begin{array}{c}\text { Rs.26212/- } \\
\text { (if accommodation } \\
\text { provided-Rs.22784/-) }\end{array}$ & $\begin{array}{c}29 \\
\text { [SC-5; ST-2; } \\
\text { OBC-6; UR-15; } \\
\text { PWD (UR)-1] }\end{array}$ & $\begin{array}{c}30 \\
\text { Years* }\end{array}$ \\
\hline
\end{tabular}

* Relaxation of 5 years for SC/ST and 3 years for OBC candidates for the posts reserved For details regarding qualification and experience, please visit CFTRI website http://www.cftri.com on or after $\mathbf{1 0 . 1 0 . 2 0 0 9}$ or refer to the Employment News issue dated 10.10.2009. Last date for receipt of completed application is 23.11.2009.

File No. FT/15(754)/09-E.I
$\mathrm{Sd} /-$

Controller of Administration 